\title{
Development of The Students Social Intelligence as The Future Teachers
}

\author{
Aliya Sankhayeva, Buketov Karaganda University, Republic of Kazakhstan, aliya_s08@mail.ru, ORCID: \\ 0000-0002-4892-0012 \\ Larissa Shkutina, Buketov Karaganda University, Republic of Kazakhstan, arlarisa@yandex.ru, ORCID: \\ 0000-0002-9370-2946 \\ Natalya Mirza, Buketov Karaganda University, Republic of Kazakhstan,d61975@rambler.ru, ORCID: 0000- \\ 0001-8938-1812 \\ Viktoriya Nikolayeva, Buketov Karaganda University, Republic of Kazakhstan, NWW@mail.ru, ORCID: \\ 0000-0002-1528-5788
}

Gulmira Shraimanova, Buketov Karaganda University, Republic of Kazakhstan, gulken69@mail.ru, ORCID: 0000-0001-6543-5193

\begin{abstract}
Object. This article discusses the problem of studying social intelligence as an important professional quality of future teachers. The researche is conducted through the resolution of the contradiction between the low level of development of social intelligence of students of pedagogical specialties and the society's demand for teacher training, including effective interactions and constructive communication with all stakeholders in the education system. The aim of the article is to theoretically substantiate and experimentally prove the need for the development of social intelligence of future teachers at the stage of study at university.
\end{abstract}

Methods. The traditional (classical) analysis is used, based on perception, understanding, comprehension and interpretation; an experiment consisting of three stages: ascertaining, forming and controlling; method of mathematical data processing. Diagnostic Methods: Social Intelligence by J.P. Guilford; Emotional Intelligence by G.S. Hall; K. Thomas, R. Kilmann Conflict Mode Instrument.

Results and discussions. The study shows that socio-psychological training had a positive impact on the development of social intelligence. Students of the experimental group (EG) significantly improved the results in understanding other people and building effective relationships, they easily get along in the team, have good social adaptation, have empathy, emotional intelligence, and in a conflict situation they try to find a constructive solution and solve the problem. Students in the control group (CG) also had changes in the level of development in the level of positive, but these changes are not significant in comparison with the EG.

Conclusions. The authors makes conclusion that the need for the development of social intelligence for the professional activities of future teachers, the positive impact of socio-psychological training in the development of social intelligence. Further studies of the teacher's social intelligence should be aimed at studying gender differences in the development of social intelligence of students of pedagogical specialties, a comparative analysis of the development of social intelligence of young teachers and teachers with a long pedagogical experience.

Keywords: social intelligence, emotional intelligence, conflict behavior, future teachers, sociopsychological training, higher education, diagnostics.

$\begin{array}{lll}\text { Received: } 15.11 .2020 & \text { Accepted: 20.12.2020 } & \text { Published: 05.01.2021 }\end{array}$

\section{INTRODUCTION}

The dynamism of society, the complexity of social reality, the increase in the number of contacts in various spheres of life make high demands on the training of teachers (Navarro-Patón et al., 2018; Mohd Zaki Mohd Amin, Radzuwan AB Rashid, Kamarul Shukri Mat The, 2019; Anastasiou, 2020).

The basis of pedagogical activity is interaction with people, the establishment of effective relationships with students, parents, other teachers, as well as everyone who is interested in the quality of education. Consequently, the effectiveness of a teacher's professional activity depend does not only on the level of specialist skill, but also on the ability of a person to establish reliable and constructive relationships with a wide range of people. In this regard, the study of social intelligence is gaining great interest. The development of new social knowledge and skills is a requirement for a person in a rapidly changing world. Acquired skills should promote understanding and interpretation of ongoing social 
changes, awareness of the behavior and actions of other people.

According to the Professional Standard "Teacher", which was adopted in the Republic of Kazakhstan on June 8, 2017 (Professional Standard "Teacher", 2017), pedagogical activity is not a direct impact of one person on another, but their interaction. Accordingly, in this standard, the socio-communicative function is highlighted, according to which the teacher's knowledge, skills and abilities to interact with the professional community and with all stakeholders in the education system are specified, that is, the teacher must have the knowledge:

- the basics of professional-psychological communication;

- forms and methods of cooperation in the professional community, including the network community;

- forms and methods of interaction with various social groups (external education stakeholders);

- the basics of professional leadership;

- ways of teamwork and professional cooperation in the framework of the policy of educational organization.

Own skills:

- independently build their activities, based on knowledge of the basics of professional and pedagogical communication;

- in collaboration with colleagues use the methods of teamwork and professional cooperation in the framework of the policy of educational organization;

- independently initiate innovative ideas that unite educational stakeholders.

In order to successfully apply these knowledge, abilities and skills in pedagogical activity, it is necessary to pay attention to the development of social intelligence, since it is this quality that will help the teacher more effectively implement professional activities.

Despite the high importance of social intelligence for specialists in the education system, it is not given sufficient attention in the training of teachers. Accordingly, our study is aimed at resolving the contradiction between the low level of development of social intelligence of students of pedagogical specialties and the requirement of society for professional training of a teacher, including effective interactions and constructive communications with all stakeholders in the education system.

Thus, social intelligence takes on the importance of a professionally important quality, both for the teacher and for any person striving for successful labor and social activities. Consequently, the development of social intelligence must be started at university when preparing future teachers.

The aim of the article is to theoretically substantiate and experimentally prove the need for the development of social intelligence of future teachers at the stage of study at university.

The objectives of the article:

- To analyze the state of the problem of social intelligence in modern science.

- To study the level of development of social intelligence among students of pedagogical specialties.

- To develop and test a program of socio-psychological training on the development of social intelligence among students of pedagogical specialties.

\section{MATERIALS AND METHODS}

The study involved 202 students of pedagogical specialties of E.A.Buketov Karaganda University (Karaganda, Republic of Kazakhstan). By random selection, students were divided into CG - 98 people and EG - 104 people. The experiment was conducted in the 2018-2019 academic year.

To solve the aim and objectives of the study, we used a theoretical analysis of the psychological and pedagogical literature on the research problem, quantitative and qualitative data analysis, methods of mathematical statistics. An experiment was also used as the main empirical research method. The experiment consisted of three stages: ascertaining, forming and controlling.

At the ascertaining and controlling stages, we used diagnostic methods:

- Social Intelligence by J.P. Guilford;

- Emotional Intelligence by G.S. Hall;

- K. Thomas, R. Kilmann Conflict Mode Instrument.

At the forming stage, we introduced the socio-psychological training developed by us, where only the EG took part.

To prove the effectiveness of the implemented program, the method of mathematical statistics (K. Pearson's Linear Correlation Coefficient) was used, where the proportionality of the variability of the variables under consideration was calculated using the following formula: 


$$
r_{y x}=\frac{\mathrm{n} \cdot \sum\left(\mathrm{x}_{\mathrm{i}} \cdot \mathrm{y}_{\mathrm{i}}\right)-\left(\sum \mathrm{x}_{\mathrm{i}} \cdot \sum \mathrm{y}_{\mathrm{i}}\right)}{\sqrt{\left[\mathrm{n} \cdot \sum \mathrm{x}_{\mathrm{i}}^{2}-\left(\sum \mathrm{x}_{\mathrm{i}}\right)^{2}\right] \cdot\left[\mathrm{n} \cdot \sum \mathrm{y}_{\mathrm{i}}^{2}-\left(\sum \mathrm{y}_{\mathrm{i}}\right)^{2}\right]}},
$$

where $r_{x y}$ - the Pearson Correlation Coefficient;

$\mathrm{x}_{\mathrm{i}}$ - values taken in the sample $\mathrm{x}$;

$\mathrm{y}_{\mathrm{i}}$ - values taken in the sample $\mathrm{y}$;

$\mathrm{n}$ - the number of subjects.

\section{LITERATURE REVIEW}

The concept of "social intelligence" refers to one of the initial abilities in the field of psychology - it was proposed in 1920 by E.L. Thorndike as the ability to understand other people and act wisely in relation to others. From the point of view of E. Thorndike, the object of social intelligence is the system of social relations (1920).

In the modern period, interest in the social intelligence of scientists is only increasing, for example, Jeungmin Lee, Jerald D. Kralik, Jaeseung Jeong (2018) in their study consider the general architecture for social intelligence in the human mind and brain. Matt I. Browna, Adrianna Ratajskab, Shannon L. Hughesc, Julie B. Fishmand, Elisa Huertae, Christopher F. Chabrisf (2019) offer their social shapes test (SST), designed to study social intelligence. SST uses animations based on clinical and social neurobiological research. This test can be used alone or in combination with other tests. Xavier Job, Louise Kirsch, Sandra Inard, Gabriel Arnold, Malika Auvray (2019) study the relationship of individual differences in a person's perception of spatial perspective with social intelligence. The authors determined that a strong rationale for their natural spatial perspective is associated with high social intelligence. Kelsey R. McDonald, John M. Pearson (2019) reviewing advances in cognitive and computational approaches, argue that advances in artificial intelligence provide valuable tools for modeling social interactions. The authors call for a combination of these approaches to combine the best to advance social intelligence. Anastasia A. Katou, Pawan S. Budhwar, Charmi Patel (2020) note in their research that the social intelligence of a leader has a stronger positive influence on the creativity of subordinates compared to performance through exploitation.

In the concept of A.I. Savenkov (2018), a model of social intelligence is presented, where three groups of components that make up social intelligence are distinguished:

1) cognitive: people;

- social knowledge - knowledge about people, knowledge of special rules, understanding of other

- social memory - memory for names, faces;

- social intuition - assessment of feelings, determination of mood, understanding of the motives of other people's actions, the ability to adequately perceive the observed behavior within the social context;

- social forecasting - the formulation of plans of one's own actions, tracking one's own development, reflection of one's own development and assessment of unused alternative opportunities;

2) emotional:

- social expressiveness - emotional expressiveness, emotional sensitivity, emotional control;

- empathy - the ability to enter the position of other people, put yourself in the place of another (to overcome communicative and moral egocentrism);

- the ability to self-regulation - the ability to regulate their own emotions and their own mood;

3) behavioral:

- social perception - the ability to listen to the interlocutor, an understanding of humor;

- social interaction - the ability and readiness to work together, the ability to collective interaction and, as the highest type of this interaction, collective creativity;

- social adaptation - the ability to explain and convince others, the ability to get along with other people, openness in relationships with others.

So, social intelligence is defined as the ability of a person to respond to social situations of everyday life. Social intelligence will not include feelings or emotions evoked by other people in us. It includes a person's ability to understand others and respond in such a way that effective communication is achieved.

The results of scientific research in the field of social intelligence are widely used in psychology, pedagogy and are being introduced into educational practice.

The social intelligence of a teacher determines the level of adequacy and success of his social and communicative interactions with other subjects of the educational process.

For example, Ardakh Yermentaeyeva, M.D. Aurenova, Elmira Uaidullakyzyphd, Almira 
Ayapbergenovaphd, Kamshat Muldabekovaphd (2014) define the social intelligence of future teachers as a cognitive component of communicative competence. The authors consider social intelligence as the ability to adequately understand and evaluate their own behavior and the behavior of other people. M. Afzalur Rahima, Ismail Civelekab, Feng Helen Liangab (2015) present a structural model of the relationship between teachers and department staffs at state university in the United States and define social intelligence as the ability to keep abreast of relevant social situations, effectively manage situational problems, understand the problems and feelings of other people, and also build and maintain positive relationships in social conditions. Della C. Loflina, Christopher T. Barryb (2016) study youthful social intelligence, as well as gender differences in social intelligence. K.S. Kenzhebayeva (2016) in her work gives a scientific and theoretical justification of the psychological characteristics of the development of social intelligence of future teachers, she developed a theoretical and structural model of the development of social intelligence with the aim of training future teachers. A.N. Umirbekova (2018) explores the theoretical and methodological justification for the development of social intelligence of future primary school teachers. The author has developed a methodology for the development of social intelligence of future primary school teachers, tested the structurally-meaningful model, and presented scientific and methodological recommendations.

Thus, social intelligence is necessary for a teacher for effective interpersonal interaction and successful socialization. Social intelligence implements the cognitive processes of a person, provides an understanding of the actions and actions of people, an understanding of a person's speech production, as well as his non-verbal reactions (facial expressions, postures, gestures). It is a cognitive component of a person's communicative abilities and a professionally important quality in professions of the "person-toperson" type. Being an important quality for a teacher, social intelligence contributes to the establishment of effective communication, as well as constructive interaction with all participants in the educational process and external stakeholders, which is necessary in modern education.

Thus, from the above, it can be established that social intelligence has a close relationship with emotional intelligence. Developed emotional intelligence contributes to career growth (Stéphane Côté, 2017), overcoming distress (Moshe Zeidner, Gerald Matthews, 2016), increasing the level of self-efficacy, which is an assessment of the individual's own abilities to cope with certain tasks in any situation (Carlos Salavera, Pablo Usán, Laurane Jarie, 2017).

This served as the basis for studying the level of development of social intelligence of students of pedagogical specialties.

\section{RESULTS AND DISCUSSIONS}

To study the initial level of development of social intelligence, students of pedagogical specialties of the Karaganda State University named after Academician E.A. Buketov, a ascertaining experiment was conducted. In the ascertaining experiment, both CG and EG took part simultaneously.

The first was a diagnostic method for the study of social intelligence by J.P. Guildford, which was developed in the 60s of the XX century by J.P. Guilford. The method consists of standardized tests aimed at diagnosing social intelligence, that is, the ability to understand and predict the behavior of people in different life situations, to recognize the intentions, feelings and emotional states of a person by nonverbal and verbal expression.

The method includes four subtests, three of them are compiled on non-verbal stimulus material and one on verbal. Subtests diagnose four abilities in the structure of social intelligence: knowledge of classes, systems, transformations and results of behavior. Each subtest contains from 12 to 15 tasks.

The results of the study of social intelligence are shown in Table 1.

Table 1. Social Intelligence Research

\begin{tabular}{|l|l|l|l|}
\hline Subtests & Ability Levels & CG \% & EG \% \\
\hline \multirow{3}{*}{$\begin{array}{l}\text { Stories } \\
\text { completion }\end{array}$} & high & 0 & 0 \\
\cline { 2 - 4 } & above average & 26,5 & 24,0 \\
\cline { 2 - 4 } & average & 26,5 & 26,9 \\
\cline { 2 - 4 } & below average & 42,9 & 43,3 \\
\cline { 2 - 4 } & low & 4,1 & 5,8 \\
\hline Group expression & high & 0 & 0 \\
\cline { 2 - 4 } & above average & 15,3 & 17,3 \\
\cline { 2 - 4 } & average & 53,1 & 50,9 \\
\cline { 2 - 4 } & below average & 23,5 & 21,2 \\
\cline { 2 - 4 } & low & 8,1 & 10,6 \\
\hline
\end{tabular}




\begin{tabular}{|l|l|l|l|}
\hline Verbal expression & high & 7,1 & 7,7 \\
\cline { 2 - 4 } & above average & 11,2 & 13,4 \\
\cline { 2 - 4 } & average & 41,8 & 40,4 \\
\cline { 2 - 4 } & below average & 23,5 & 20,2 \\
\cline { 2 - 4 } & low & 16,4 & 18,3 \\
\hline \multirow{4}{*}{ Suppleme } & high & 0 & 0 \\
\cline { 2 - 4 } & above average & 7,1 & 7,7 \\
\cline { 2 - 4 } & average & 29,6 & 28,8 \\
\cline { 2 - 4 } & below average & 55,2 & 53,9 \\
\cline { 2 - 4 } & low & 8,1 & 9,6 \\
\hline Middle Index & high & 1,8 & 1,9 \\
\cline { 2 - 4 } & above average & 15,0 & 15,6 \\
\cline { 2 - 4 } & average & 37,7 & 36,7 \\
\cline { 2 - 4 } & below average & 36,3 & 34,7 \\
\cline { 2 - 4 } & low & 9,2 & 11,1 \\
\hline
\end{tabular}

According to Subtest 1 of the "Stories with completion", a high level was not detected, 26.5\% of the subjects of the CG and $24.0 \%$ of the EG have a level above the average, that is, these students are able to anticipate the consequences of behavior. They are able to analyze the real situation of communication and predict the future actions of people, they are able to design a strategy for their behavior to achieve the goal. Further, $26.5 \%$ of the respondents from the CG and $26.9 \%$ of the respondents from the EG showed an average level of ability, this indicates an average level of knowledge about the rules governing human behavior, as well as insufficient skills to navigate the non-verbal reaction of participants in the educational process. The result is a below the average in the subtest, namely $42.9 \%$ in the CG and $43.3 \%$ in the EG showed respondents who do not always understand the relationship of people's behavior and its consequences, because of this they often end up in conflict situations. According to this subtest, a certain part of the respondents also has a low level: $4.1 \%$ of the tested CG and 5.8\% - the EG. These students can often make mistakes, constantly get into conflict situations, because misinterpret the results of the actions of other people, poorly orientated in the norms and rules of behavior accepted in society, and sometimes violate them intentionally.

In the second Subtest, the "Group expression" as well as in the first subtest of the high level were not determined. But the level above the average was shown by $15.3 \%$ of the respondents from the CG and $17.3 \%$ from the EG, the subjects often correctly assess the states, feelings, intentions of people by their non-verbal manifestations: facial expressions, postures, gestures. They attach importance to non-verbal communication, are sensitive to it, which helps them understand other people. Subjects with the average level of development (53.1\% - CG, 50.9\% - EG) are not always attentive to non-verbal reactions when interacting with other people, they understand the body language, but may not take it into account in a communication situation. The level is the below average level for this subtest: $23.5 \%$ in the CG and $21.2 \%$ in the EG were shown by subjects who do not have good sign and body language, in communications they often focus on the verbal side of communication and do not take into account its non-verbal content. It can also be noted that there is the low level in the subtest under consideration, namely $8.1 \%$ in the CG and $10.6 \%$ in the EG, that is, such students often make mistakes in understanding the meaning of the words of the interlocutor, because misinterpret his non-verbal reactions.

The results of the third Subtest "Verbal expression" showed the presence of the high level of ability in $7.1 \%$ of respondents in the $\mathrm{CG}$ and $7.7 \%$ of respondents in the EG, these students are highly sensitive to the nature and shades of human relationships, this contributes to a quick and accurate understanding of the speech expression of the interlocutor. $11.2 \%$ of the respondents from the CG and $13.4 \%$ from the EG have the above average level. These students have a good ability to find the appropriate tone of communication with different people in different situations, have enough baggage of role-playing behavior. Subjects who showed the average level $(41.8 \%$ - CG and $40.4 \%$ - EG) do not often show role plasticity, because sometimes difficulties arise in understanding the verbal reactions of the interlocutor in the context of a particular situation. $23.5 \%$ of the respondents from the CG and $20.2 \%$ of the respondents from the EG have the level below the average, which indicates a poor understanding of the meaning of verbal communication in various communication situations. Nevertheless, the low level of abilities $(16.4 \%$ - CG and $18.3 \%$ - EG) suggests that students have difficulty understanding human verbal reactions, make mistakes in interpreting the words of the interlocutor, speech is incoherent, often does not make sense .

According to the indicators of the fourth Subtest "History Supplement", students do not have the 
high level of ability. The above average level showed $7.1 \%$ of the respondents in the CG and $7.7 \%$ of the respondents in the EG. These students are able to understand interpersonal relationships in dynamics, when interacting with participants in the educational process, they can feel a change in the situation and the logic of its development. The average level of abilities in the subtet under consideration $29.6 \%$ - CG and $28.8 \%$ - EG) indicates insufficient skills to understand the specific behavior of the interlocutor, they do not always recognize the intentions and internal motives of the participants in communication, although they have a good level of mental operations. 55.2\% of the respondents from the CG and $53.9 \%$ the EG are the below average level, that is, these subjects have difficulties with understanding the logic of the development of the interaction situation, the logical inference is poorly developed, which affects the lack of ability to recognize the consequences of certain behaviors of people, poorly orientated in nonverbal reactions of a person, as well as norms and rules of behavior in society. Accordingly, the subjects showed the low level both in the CG (8.1\%) and in the EG (9.6\%). These students have difficulties in understanding the situation of interpersonal interaction, are not aware of the needs and motives of people's behavior, which affects poor adaptation to relationships with different people.

Thus, according to the average indicator for this diagnosis, $1.8 \%$ of the respondents from the $\mathrm{CG}$ and $1.9 \%$ of the respondents from the EG have the high level of social intelligence, that is, these students can extract maximum information from people's behavior, perfectly understand the language of non-verbal communication, are visionary in relations with interlocutors, which affects their successful social adaptation. $15.0 \%$ of the respondents from the CG and 15.6\% from the EG have the above average level; these students easily get along in a team, have developed organizational skills, are open to communication, friendly, but do not always strive for psychological proximity during communication, which does not reduce their communication skills. Students with tact and contact with people have the average level of social intelligence in the CG (37.7\%) and the EG (36.7\%), but they are not always able to predict the behavior and reaction of the interlocutor in a conversation, they are sociable, but do not pay enough attention to non-verbal reactions of a person. $36.3 \%$ of the respondents from the CG and $34.7 \%$ of the respondents from the EG have the level below the average. These subjects experience difficulties in interacting with other people, poor adaptation in society. The low level, namely, $9.2 \%$ of the respondents from the CG and $11.1 \%$ from the EG showed students who do not need to interact with other people, experience anxiety when communicating, have low organizational skills, and therefore do not understand the language of non-verbal communication, which leads to conflicts and not achieving communication goals.

Next, a diagnostic method was conducted to study the emotional intelligence of G.S. Hall. This technique is aimed at identifying a person's ability to control and understand their emotions, communication skills and understand the feelings of other people. These qualities are determined by the level of emotional intelligence.

Emotional intelligence can change throughout life. If a person strives for self-development, inner harmony, learns to interact with others, then emotional intelligence will grow. It can remain unchanged in the absence of the individual's desire for self-improvement.

The higher the level of emotional intelligence in a person, the easier it is for him to build relationships with people. Such a person easily achieves his goals, he lives in harmony with himself and others. Owners of a low level of emotional intelligence, as a rule, may feel discomfort in the team, as they do not understand the emotions and moods of other people, which can even lead to conflict situations. Often, they cannot control their mood and behavior, as they are not aware of the underlying causes of their manifestations. It is difficult for such people to make contacts, and accordingly, it is more difficult to achieve their goals and grow not only spiritually, but also professionally. In this regard, we believe that emotional intelligence is interconnected with social intelligence and is an important part of the professionalism of future teachers.

The G.S.Hall method is proposed to identify the ability to understand personality relationships that are represented in emotions and manage the emotional sphere based on decision making. The test consists of 30 statements and contains 5 scales:

- Self-Awareness is the ability to read and understand your own emotions and moods. People with high emotional awareness are more than others aware of their internal state;

- Self-Management is the ability to control your emotions, and to behave reliably, emotional flexibility, in other words, arbitrary control of own emotions;

- Self-Motivation - the management of own behavior through the control of emotions; intrinsic motivation means that an individual is driven to meet personal needs and goals, rather than being motivated by external rewards such as money, fame, and recognition;

- Social Awareness (or Empathy) is an understanding of the emotions of other people, the ability to empathize with the current emotional state of another person, as well as the willingness to provide 
support, the ability to understand a person's condition by facial expressions, gestures, shades of speech, posture;

- Relationship Management (or Social Skills) - the ability to influence the emotional state of others, to develop meaningful interpersonal relationships and to communicate clearly with others.

The results of the study of emotional intelligence are presented in Table 2.

Table 2. Emotional Intelligence Research

\begin{tabular}{|c|c|c|c|}
\hline Scales & Levels & KG \% & EG \% \\
\hline \multirow[t]{3}{*}{ Self-Awareness } & high & 17,3 & 15,8 \\
\hline & average & 33,2 & 38,3 \\
\hline & low & 49,5 & 45,9 \\
\hline \multirow[t]{3}{*}{ Self-Management } & high & 3,8 & 5,1 \\
\hline & average & 14,4 & 18,2 \\
\hline & low & 81,8 & 76,7 \\
\hline \multirow[t]{3}{*}{ Self-Motivation } & high & 14,2 & 15,8 \\
\hline & average & 31,5 & 30,2 \\
\hline & low & 54,3 & 54,0 \\
\hline \multirow{3}{*}{$\begin{array}{l}\text { Social Awareness (or } \\
\text { Empathy) }\end{array}$} & high & 12,1 & 13,2 \\
\hline & average & 29,3 & 26,8 \\
\hline & low & 58,6 & 60,0 \\
\hline \multirow{3}{*}{$\begin{array}{l}\text { Relationship } \\
\text { Management (or Social } \\
\text { Skills) }\end{array}$} & high & 15,7 & 14,8 \\
\hline & average & 31,2 & 33,1 \\
\hline & low & 53,1 & 52,1 \\
\hline \multirow[t]{3}{*}{ Middle Index } & high & 12,6 & 12,9 \\
\hline & average & 27,9 & 29,3 \\
\hline & low & 59,5 & 57,8 \\
\hline
\end{tabular}

According to the diagnostic results, we see that only $12.6 \%$ of the respondents from the CG and $12.9 \%$ of the respondents from the EG have high indicators, that is, these students understand their emotions and their consequences, are able to restrain destructive experiences, strive for self-realization, understand the feelings of other people, able to persuade and compromise.

The average level is $27.9 \%$ of students in the CG and $29.3 \%$ of students in the EG. These test subjects do not always recognize their strengths and weaknesses, show flexibility with difficulty, therefore they are wary of changing the situation, they know how to work in a team, but sometimes there is fear of complex goals, are attentive to the interlocutor, but are not interested in his mood and emotions, help is needed when speaking to an audience.

The largest number of respondents showed a low level - this is 59.5\% - CG, 57.8\% - EG. These students are not self-confident, lose their temper in stressful situations, do not admit their mistakes, are afraid of failures, tolerance to other people's shortcomings is not developed, they are not convincing in speech, they have poor communication skills.

The following was a diagnostic method of K. Thomas, R. Kilmann Conflict Mode Instrument. Using this questionnaire, people's behavior in a conflict situation is measured. To describe the types of people's behavior in conflict situations, the author uses a two-dimensional model of conflict management, the fundamental dimensions of which are cooperation related to the person's attention to the interests of other people involved in the conflict and assertiveness, which is characterized by an emphasis on protecting one's own interests. According to these two main dimensions, K. Thomas identifies the following methods of conflict management: rivalry, cooperation, compromise, avoidance, adaptation. This questionnaire consists of 30 questions, where the students had to choose the appropriate answer.

Diagnostic results are shown in Table 3.

Table 3. Conflict Behavior Research

\begin{tabular}{|l|l|l|l|}
\hline Criteria & Levels & KG \% & EG \% \\
\hline Rivalry & high & 57,3 & 55,8 \\
\cline { 2 - 4 } & average & 28,2 & 30,3 \\
\cline { 2 - 4 } & low & 14,5 & 13,9 \\
\hline \multirow{4}{*}{ Cooperation } & high & 12,1 & 15,3 \\
\cline { 2 - 4 } & average & 54,5 & 57,1 \\
\cline { 2 - 4 } & low & 33,4 & 27,6 \\
\hline
\end{tabular}




\begin{tabular}{|l|l|l|l|}
\hline Compromise & high & 48,9 & 51,1 \\
\cline { 2 - 4 } & average & 29,1 & 28,3 \\
\cline { 2 - 4 } & low & 22,0 & 20,6 \\
\hline \multirow{4}{*}{ Avoidance } & high & 67,1 & 64,4 \\
\cline { 2 - 4 } & average & 20,1 & 21,8 \\
\cline { 2 - 4 } & low & 12,8 & 13,8 \\
\hline Adaptation & high & 11,4 & 10,5 \\
\cline { 2 - 4 } & average & 33,8 & 35,1 \\
\cline { 2 - 4 } & low & 54,8 & 54,4 \\
\hline
\end{tabular}

Based on the diagnostic results, we see:

- according to the criterion of "rivalry", students with a high level prevail (57.3\% - CG, 55.8\% - EG), that is, most students impose on the other side their preferred decisions;

- according to the criterion of "cooperation", only 12.1\% - CG and 15.3\% - EG have a high level, that is, these test subjects are focused on constructive discussion of the problem, considering the other side not as an adversary, but as an ally in finding a solution, as cooperation is considered the most effective strategy for behavior in a conflict, we believe the number of students with a high level is insufficient;

- according to the "compromise" criterion, the majority of respondents showed good results (48\% CG, $51 \%$ - EG), that is, opponents have a desire to end the conflict by partial concessions, abandon some of the previously put forward claims, recognize the claims of the other side as partially justified, but nevertheless, respondents with a low level are also sufficient (23\% - CG, 21\% - EG), which indicates the inability of the individual to make compromises and concessions;

- according to the criterion "avoidance" or avoiding the solution of the problem, students with a high level prevail (67.1\% - CG, 64.4\% - EG), that is, these respondents in a conflict situation try to avoid the conflict, avoid it by any means, however, the conflict is not resolved, but temporarily fades, but the problem remains;

- according to the criterion of "adaptation" or concession, the respondents are predominantly low (54.8\% - CG, 54.4\% - EG), which indicates an unwillingness to give up their positions, these subjects try to prove their case by any means without thinking about the negative consequences.

According to the results of a ascertaining experiment, we see that students of pedagogical specialties have insufficiently developed social intelligence, as well as other personality qualities that affect social intelligence and have a direct impact on pedagogical activity: emotional intelligence and the prevalence of conflict behavior. What will affect on future professional activities. Since the university the main organizational forms of training are lectures, practical lessons, students independent work with teacher and students self directed learning, which are aimed at the formation of knowledge, skills, and we forget about the need to develop such personal qualities of students that will help him build effective communication in the future, constructive interaction, as well as not only understand, but also realize that all participants in the educational process can have their own opinion that is different from his opinion and they have the right to it. In this regard, it became necessary to organize a forming experiment, which includes socio-psychological training aimed at developing the social intelligence of future teachers. Only the EG participated in the forming experiment.

Figure 1 shows a program of socio-psychological training. 


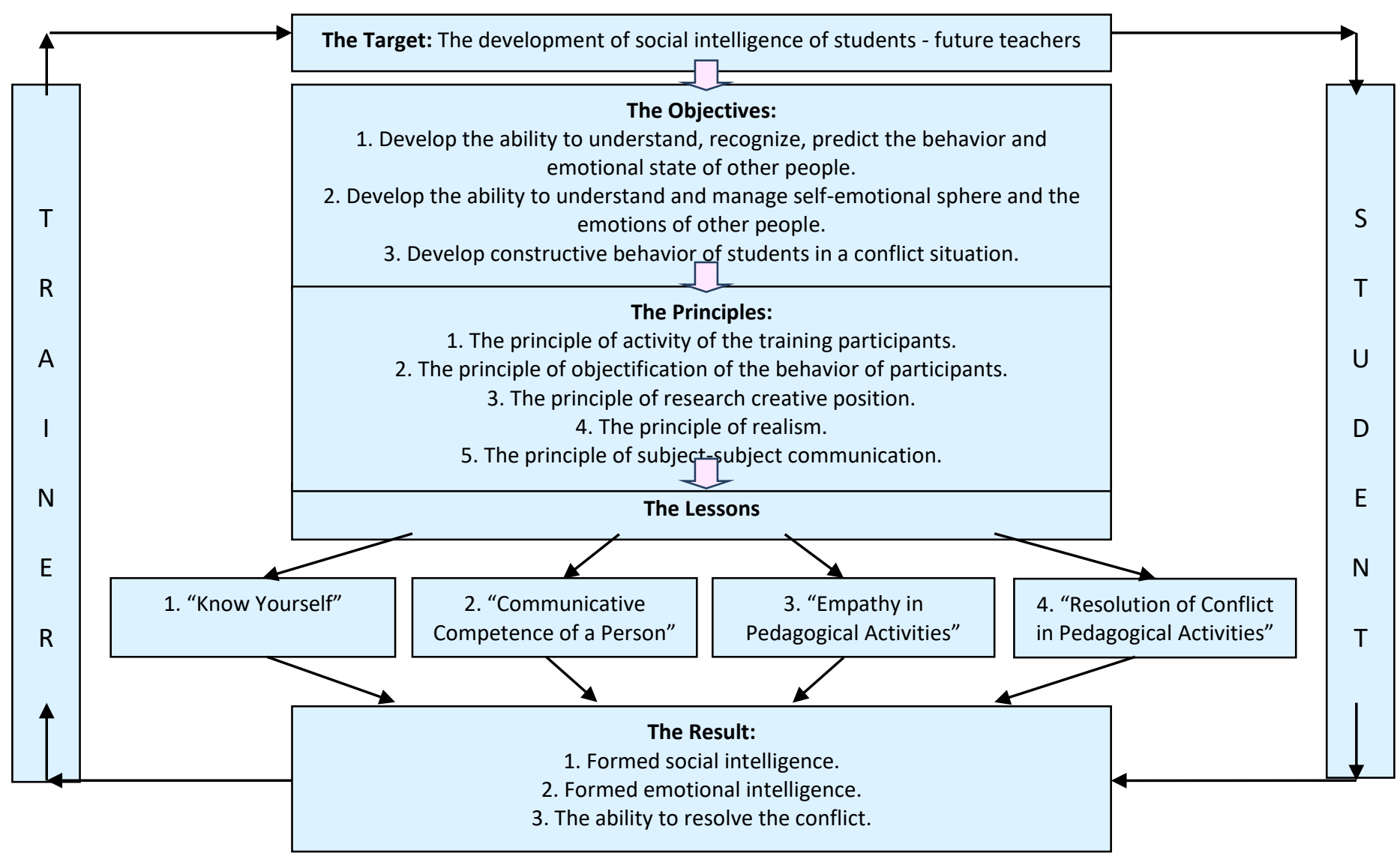

Figure 1. Program of socio-psychological training

The program of socio-psychological training was developed in accordance with the psychological and pedagogical principles (Vachkov, 2007):

1. The principle of activity of the training participants. The principle of activity is ensured due to the fact that the participants are offered a wide variety of activities, schemes for observing the game situation, and rotation of players.

2. The principle of objectification of the behavior of participants. A universal means of objectification is feedback. When organizing feedback, it is important to observe the following rules:

- pay attention to behavior based on observation (what I see, what I hear, what I feel), and not on interpretations;

- use the description in relation to what is happening "here and now";

- pay attention to new opportunities that come if a person is not afraid to experiment.

3 . The principle of research creative position. The implementation of the principle requires the creation of an environment characterized by problematics, uncertainty and unassessed attitude to the participants.

4. The principle of realism is realized due to the correspondence of means and methods to the goals of the training, game situations correspond to the real experience of the participants, goals and level of difficulty correspond to the experience and capabilities of the group.

5. The principle of subject-subject communication requires observance of the rules of psychological safety in communications, personification of statements (self-statement), respect for the personality of another.

Socio-psychological training consisted of four sessions of 6 hours. Students were offered the following topics: "Know Yourself", "Communicative Competence of a Person", "Empathy in Pedagogical 
Activities", "Resolution of Conflict in Pedagogical Activities". Training sessions included tasks and exercises to stimulate personal self-knowledge and self-determination of students; increasing motivation for teaching activities; development of effective communication skills, the ability to analyze, generalize various points of view; forming of skills of non-reflective and reflective listening, "I-statements"; development of the ability to maintain productivity in situations of pressure and stress, development of the stress resistance, maintain confidence and calm in various situations; development of skills of interaction with people of different levels, to find a common language with them; awareness of the positive possibilities of constructive ways to resolve conflicts.

Thus, during socio-psychological training, students were faced with situations relevant to the process of their real professional activity. During the training, mechanisms were launched that affect the processes of change, such as spontaneous or planned self-presentation and self-disclosure of participants, feedback and reflection. Also, socio-psychological training contributed not only to solving current problems, but also to preventing them in the future.

After organizing the forming experiment, in order to confirm the effectiveness of the program of socio-psychological training we developed, a controlling experiment was organized. In the controlling experiment, both the CG and the EG took part simultaneously. At this stage, the same diagnostic methods were used as at the ascertaining stage.

According to the results of the diagnosis of social intelligence by J. Guildford, we obtained the following results (table 4):

Table 4. Summary Table of Social Intelligence Research

\begin{tabular}{|c|c|c|c|c|c|}
\hline \multirow[t]{2}{*}{ Subtests } & \multirow[t]{2}{*}{ Ability Levels } & \multicolumn{2}{|c|}{ Ascertaining stage } & \multicolumn{2}{|c|}{ Controlling stage } \\
\hline & & CG \% & EG \% & CG \% & EG \% \\
\hline \multirow{5}{*}{$\begin{array}{l}\text { Stories with } \\
\text { completion }\end{array}$} & High & 0 & 0 & 3,1 & 29,8 \\
\hline & above average & 26,5 & 24,0 & 28,5 & 33,7 \\
\hline & Average & 26,5 & 26,9 & 30,6 & 19,2 \\
\hline & below average & 42,9 & 43,3 & 34,7 & 16,3 \\
\hline & Low & 4,1 & 5,8 & 3,1 & 1,0 \\
\hline \multirow{5}{*}{$\begin{array}{l}\text { Group } \\
\text { expression }\end{array}$} & High & 0 & 0 & 2,0 & 33,7 \\
\hline & above average & 15,3 & 17,3 & 17,3 & 28,8 \\
\hline & Average & 53,1 & 50,9 & 56,2 & 22,1 \\
\hline & below average & 23,5 & 21,2 & 19,4 & 13,5 \\
\hline & Low & 8,1 & 10,6 & 5,1 & 1,9 \\
\hline \multirow{5}{*}{$\begin{array}{l}\text { Verbal } \\
\text { expression }\end{array}$} & High & 7,1 & 7,7 & 8,1 & 33,7 \\
\hline & above average & 11,2 & 13,4 & 15,3 & 28,8 \\
\hline & Average & 41,8 & 40,4 & 42,9 & 26,0 \\
\hline & below average & 23,5 & 20,2 & 24,5 & 8,6 \\
\hline & Low & 16,4 & 18,3 & 9,2 & 2,9 \\
\hline \multirow{5}{*}{$\begin{array}{l}\text { History } \\
\text { Supplement }\end{array}$} & High & 0 & 0 & 2,0 & 31,7 \\
\hline & above average & 7,1 & 7,7 & 12,2 & 26,0 \\
\hline & Average & 29,6 & 28,8 & 30,7 & 25,0 \\
\hline & below average & 55,2 & 53,9 & 48,0 & 15,4 \\
\hline & Low & 8,1 & 9,6 & 7,1 & 1,9 \\
\hline \multirow[t]{5}{*}{ Middle Index } & High & 1,8 & 1,9 & 3,8 & 32,2 \\
\hline & above average & 15,0 & 15,6 & 18,3 & 29,3 \\
\hline & Average & 37,7 & 36,7 & 40,1 & 23,1 \\
\hline & below average & 36,3 & 34,7 & 31,7 & 13,5 \\
\hline & Low & 9,2 & 11,1 & 6,1 & 1,9 \\
\hline
\end{tabular}

According to Subtest 1 "Stories with completion" at the controlling stage, we see the presence of a high level in students of the EG (29.8\%) and CG (3.1\%), while the percentage of EG subjects is much higher than that of the CG students. It can also be noted that before the experiment at the ascertaining stage, respondents with a high level were absent. These results suggest that the students of the EG began to better understand the real situation of communication and predict the actions of people, which helps them build a strategy of their behavior to achieve goals.

In the second Subtest of the "Group expression", we also see a predominance of EG students with a high level of development (33.7\%), in contrast to students from the CG (2.0\%). Compared with the results of the ascertaining stage, where respondents with a high level were not identified. Those, after the 
formative experiment, EG students are able to correctly assess the state and feelings of people according to their non-verbal manifestations, which helps them better understand other people.

The results of the third Subtest "Verbal expression" show us significant changes in the high level in the students of the EG (33.7\%) than in the students of the CG (8.1\%). Although before the experiment, students had a high level of both EG (7.7\%) and CG (7.1\%), but after the implementation of sociopsychological training in the educational process of the university, the results of the EG towards a high level increased more than four times. This indicates the development of the subjects' ability to be highly sensitive to the nature and shades of human relationships, to quickly and correctly understand the speech expression of the interlocutor, to find the appropriate tone of communication with different people in different situations, to use the rich baggage of role-playing behavior.

According to the indicators of the fourth subtest "Stories with additions" at the controlling stage, $31.7 \%$ of the students in the EG showed a high level and 2.0\% - in the CG. In contrast to the ascertaining stage, where students with a high level of development in both the EG and the CG amounted to $0 \%$. That is, in the EG, the number of subjects able to understand interpersonal relationships in dynamics increased, they can feel the change in the situation and the logic of its development, recognize the intentions and internal motives of the participants in communication, and logical inference is well developed.

Thus, when analyzing the results, we see a significant improvement in the EG, according to all subtests, the subjects showed a high level (32.2\%) and a level above the average (29.3\%), the number of subjects having a level below the average (13.5\%) and the low level $(1.9 \%)$ was significantly reduced. This means that the number of students who can build successful communication, understand a nonverbal language of communication has increased, they can extract maximum information from people's behavior, easily get on with the team, strive for psychological closeness, have organizational skills, to be friendly, can predict the behavior and reaction of the interlocutor . In the CG, we also see changes, but when compared with the EG, these changes prevail more towards the low level.

The following was a diagnostic technique to study the emotional intelligence of G.S. Hall. The summary results of the study of emotional intelligence at the ascertaining and controlling stages are presented in table 5 .

Table 5. Summary Table of Emotional Intelligence Research

\begin{tabular}{|c|c|c|c|c|c|}
\hline \multirow[t]{2}{*}{ Scales } & \multirow[t]{2}{*}{ Levels } & \multicolumn{2}{|c|}{ Ascertaining stage } & \multicolumn{2}{|c|}{ Controlling stage } \\
\hline & & CG \% & EG \% & CG \% & EG \% \\
\hline \multirow[t]{3}{*}{ Self-Awareness } & High & 17,3 & 15,8 & 21,3 & 65,8 \\
\hline & Average & 33,2 & 38,3 & 36,8 & 28,3 \\
\hline & Low & 49,5 & 45,9 & 41,9 & 5,9 \\
\hline \multirow[t]{3}{*}{ Self-Management } & High & 3,8 & 5,1 & 8,3 & 55,4 \\
\hline & Average & 14,4 & 18,2 & 28,2 & 25,8 \\
\hline & Low & 81,8 & 76,7 & 63,5 & 18,8 \\
\hline \multirow[t]{3}{*}{ Self-Motivation } & High & 14,2 & 15,8 & 21,2 & 56,3 \\
\hline & Average & 31,5 & 30,2 & 32,4 & 36,2 \\
\hline & Low & 54,3 & 54,0 & 46,4 & 7,5 \\
\hline \multirow{3}{*}{$\begin{array}{l}\text { Social Awareness (or } \\
\text { Empathy) }\end{array}$} & High & 12,1 & 13,2 & 18,3 & 63,8 \\
\hline & Average & 29,3 & 26,8 & 38,5 & 28,3 \\
\hline & Low & 58,6 & 60,0 & 43,2 & 7,9 \\
\hline \multirow{3}{*}{$\begin{array}{l}\text { Relationship } \\
\text { Management (or Social } \\
\text { Skills) }\end{array}$} & High & 15,7 & 14,8 & 18,6 & 58,4 \\
\hline & Average & 31,2 & 33,1 & 42,3 & 29,9 \\
\hline & Low & 53,1 & 52,1 & 39,1 & 11,7 \\
\hline \multirow[t]{3}{*}{ Middle Index } & High & 12,6 & 12,9 & 17,5 & 59,9 \\
\hline & Average & 27,9 & 29,3 & 35,7 & 29,7 \\
\hline & Low & 59,5 & 57,8 & 46,8 & 10,4 \\
\hline
\end{tabular}

According to the diagnostic results, we see that the level of development of emotional intelligence is much higher in the EG than in the CG, that is, $59.9 \%$ of the EG respondents effectively build relationships with people, live in harmony with themselves and others, have emotional flexibility, to be ready to support and empathize. And only $10.4 \%$ of EG respondents have a low level of development of emotional intelligence. In contrast to the CG, where only $17.5 \%$ of respondents have a high level and $46.8 \%$ of respondents have a low level.

Hence, we can say that socio-psychological training had a positive effect on changes in the 
performance of students in the EG, although in the CG we also see minor changes that are due to the continuation of the educational process and the development of students according to the plan of study at the university.

And the last one was a diagnostic method to study the conflict behavior (K. Thomas, R. Kilmann). The summary diagnostic results before and after the experiment are shown in Table 6.

Table 6. Summary Table of Conflict Behavior Research

\begin{tabular}{|l|l|l|l|l|l|}
\hline \multirow{2}{*}{ Criteria } & \multirow{2}{*}{ Levels } & \multicolumn{2}{|l|}{ Ascertaining stage } & \multicolumn{2}{l|}{ Controlling stage } \\
\cline { 3 - 6 } & & CG \% & EG \% & CG \% & EG \% \\
\hline \multirow{4}{*}{ Rivalry } & High & 57,3 & 55,8 & 52,3 & 23,3 \\
\cline { 2 - 6 } & Average & 28,2 & 30,3 & 29,4 & 30,9 \\
\cline { 2 - 6 } & Low & 14,5 & 13,9 & 18,3 & 45,8 \\
\hline Cooperation & High & 12,1 & 15,3 & 15,2 & 48,2 \\
\cline { 2 - 6 } & Average & 54,5 & 57,1 & 55,1 & 36,5 \\
\cline { 2 - 6 } & Low & 33,4 & 27,6 & 29,7 & 15,3 \\
\hline \multirow{5}{*}{ Avoidance } & High & 48,9 & 51,1 & 52,1 & 72,7 \\
\cline { 2 - 6 } & Herage & 29,1 & 28,3 & 30,1 & 12,8 \\
\cline { 2 - 6 } & Low & 22,0 & 20,6 & 17,8 & 14,5 \\
\cline { 2 - 6 } & Average & 20,1 & 64,4 & 53,8 & 25,2 \\
\cline { 2 - 6 } & Low & 12,8 & 13,8 & 23,8 & 28,6 \\
\hline Adaptation & High & 11,4 & 10,5 & 14,2 & 46,2 \\
\cline { 2 - 6 } & Average & 33,8 & 35,1 & 35,1 & 38,3 \\
\cline { 2 - 6 } & Low & 54,8 & 54,4 & 50,7 & 6,4 \\
\hline
\end{tabular}

According to the diagnostic results, we see the changes that have occurred in the indicators of conflict behavior of both the EG and the CG:

- according to the criterion of "rivalry" $45.8 \%$ of EG students have a low level, that is, these students do not impose their opinion, but try to cooperate and come to a common solution to the problem, unlike students in the CG, where a high level prevails - $52.3 \%$;

- according to the criterion of "cooperation", the results of EG students significantly increased (48.2\%), in contrast to the CG students (15.2\%), that is, most of the EG students are capable of constructive discussion of the problem, there is interaction with the other side, and not incitement to conflict;

- according to the "compromise" criterion, the results increased in the EG (72.7\%), in the CG there were small changes (52.1\%), which indicates the positive dynamics and the desire of students to resolve the conflict peacefully, through concessions and recognition of the other party's right to different opinion;

- according to the "avoidance" criterion, or avoiding solving a problem, there were more respondents in the EG with a low level (46.2\%) than in the CG $(22.4 \%)$, that is, these students seek to resolve the conflict, do not try to get away from problems, and strive for a constructive solution to it;

- according to the criterion of "adaptation" or concession, students with a high level prevail in the EG (55.3\%), in the CG their number is less (14.2\%), these students take into account the position of the opposite side, do not impose their opinion, can go on concessions to avoid negative consequences.

The control experiment shows us that socio-psychological training had a positive impact on the development of social intelligence among students in the EG. Students have significantly improved results in understanding other people and building effective relationships, they easily get along in a team, have good social adaptation, have empathy, emotional intelligence, and in a conflict situation they try to find a constructive solution and solve the problem. Students in the CG also have changes in the level of development in the direction of the positive, but these changes are not significant in comparison with the EG.

To determine the effectiveness of the socio-psychological training elaborated by us on the development of social intelligence, we investigated the statistical relationship of two variables: the CG, as a sample, where the program developed by us was not implemented, and the EG, as a sample, where the forming experiment was organized. As a result, the linear correlation coefficient $\left(r_{x \gamma}=0.973\right)$ is in the range from -1 to 1 and is close to one $(1>0.973>-1)$, which indicates a reliable relationship between the level of development of social intelligence of future teachers and the implementation of the developed social psychological training. 


\section{CONCLUSION}

Based on theoretical analysis and experimental data, we see the need for the development of social intelligence in the process of preparing a future teacher.

Thus, as a result of the study, the following conclusions can be drawn:

- social intelligence is an integral intellectual ability that determines the success of communication and social adaptation, which combines and regulates cognitive processes associated with the reflection of social objects (a person as a communication partner or group of people);

- social intelligence provides an understanding of actions, speech, as well as non-verbal behavior (gestures, facial expressions) of people. It acts as the cognitive component of the communicative abilities of the person and as a professionally important quality for professions such as "person-person";

- to study the level of development of social intelligence, we recommend using diagnostic methods: research on the social intelligence of J. Guildford, the study of the emotional intelligence of G.S. Hall, the study of the conflict behavior of K. Thomas and R. Kilmann, because collectively they give a complete picture of the phenomenon being studied;

- socio-psychological training positively affects the development of social intelligence and its implementation is necessary in the preparation of future teachers, therefore, the use of sociopsychological training as an organizational form of training will positively affect the training of specialists such as "person-person".

The study does not claim to be an exhaustive solution to all aspects of the problem of social intelligence, and has the following prospects:

- Gender differences in the development of social intelligence of students of pedagogical specialties;

- A comparative analysis of the development of social intelligence of young teachers and educators with a great pedagogical experience.

\section{REFERENCES}

Afzalur Rahima M., Ismail Civelekab, \& Feng Helen Liangab (2015). A model of department chairs' social intelligence and faculty members' turnover intention. Intelligence, 53, 65-71. Available at: https://doi.org/10.1016/j.intell.2015.09.001

Anastasia A. Katou, Pawan S. Budhwar, \& Charmi Patel (2020). A trilogy of organizational ambidexterity: Leader's social intelligence, employee work engagement and environmental changes. Journal of Business Research. Available at: https://doi.org/10.1016/j.jbusres.2020.01.043

Anastasiou S. (2020). The Moderating Effect of Age on Preschool Teachers Trait Emotional Intelligence in Greece and Implications for Preschool Human Resources Management. International journal of education and practice, 8(1), 26-36. Available at: https://doi.org/10.18488/journal.61.2020.81.26.36

Carlos Salavera, Pablo Usán, \& Laurane Jarie (2017). Emotional intelligence and social skills on selfefficacy in Secondary Education students. Are there gender differences? Journal of Adolescence, 60, 39-46. Available at: https://doi.org/10.1016/j.adolescence.2017.07.009

Della C.Loflina, \& Christopher T.Barryb (2016). «You can't sit with us»: Gender and the differential roles of social intelligence and peer status in adolescent relational aggression. Personality and Individual Differences, 91, 22-26. Available at: https://doi.org/10.1016/j.paid.2015.11.048

Jeungmin Lee, Jerald D.Kralik, \& Jaeseung Jeong (2018). A General Architecture for Social Intelligence in the Human Mind \& Brain. Procedia Computer Science, 145, 747-756. Available at: https://doi.org/10.1016/j.procs.2018.11.034

Kelsey R. McDonald, \& John M. Pearson (2019). Cognitive bots and algorithmic humans: toward a shared understanding of social intelligence. Current Opinion in Behavioral Sciences, 29, 55-62. Available at: https://doi.org/10.1016/j.cobeha.2019.04.013

Kenzhebayeva, K.S. (2016). Bolashak pedagogterdin aleumettik intellektisinin damuyndagy psihologiyalyk erekshelikter [Psychological features of the development of social intelligence of future teachers] (PhD dissertation). Astana. (in Kazakh).

Matt I.Browna, Adrianna Ratajskab, Shannon L.Hughesc, Julie B.Fishmand, Elisa Huertae, \& Christopher F.Chabrisf (2019). The social shapes test: A new measure of social intelligence, mentalizing, and theory of mind. Personality and Individual Differences, 143, 107-117. Available at: https://doi.org/10.1016/j.paid.2019.01.035

Mohd Zaki Mohd Amin, Radzuwan AB Rashid, \& Kamarul Shukri Mat The (2019). Investigating Issues and Challenges in Employing Action Research for Teacher Training in Malaysian Context. International journal of education and practice, $7(1)$, 30-40. Available at: 
https://doi.org/10.18488/journal.61.2019.71.30.40

Moshe Zeidner, \& Gerald Matthews (2016). Ability emotional intelligence and mental health: Social support as a mediator. Personality and Individual Differences, 99, 196-199. Available at: https://doi.org/10.1016/j.paid.2016.05.008

Navarro-Patón, R., Freire-Tellado, M., Basanta-Camiño, S., Barcala-Furelos, R., Arufe-Giraldez, V., \& Rodriguez-Fernández, J.E. (2018). Effect of 3 basic life support training programs in future primary school teachers. A quasi-experimental design. Medicina Intensiva (English Edition), 42(4), 207-215. Available at: https://doi.org/10.1016/j.medine.2017.06.012

Professional Standard "Teacher" (2017). Appendix to the Order of the Chairman of the Board of the National Chamber of Entrepreneurs of the Republic of Kazakhstan "Atameken". Available at: https://atameken.kz/uploads/content/files/\%D0\%9F\%D0\%A1\%20\%D0\%9F\%D0\%B5\%D0\%B4 \%D0\%B0\%D0\%B3\%D0\%BE\%D0\%B3.pdf (accessed 05.10.2020). (In Russian)

Savenkov, A.I. (2018). Struktura social'nogo intellekta [Structure of social intellect]. Sovremennaya zarubezhnaya psihologiya - Journal of Modern Foreign Psychology, 7(2), 7-15. Available at: https://doi.org/10.17759/jmfp.2018070201. (In Russian)

Stéphane Côté (2017). Enhancing managerial effectiveness via four core facets of emotional intelligence: Self-awareness, social perception, emotion understanding, and emotion regulation. Organizational Dynamics, 46(3), 140-147. Available at: https://doi.org/10.1016/j.orgdyn.2017.05.007

Thorndike, E.L. (1920). Intelligence and its uses. Harper's Magazine, 140, 227-235.

Umirbekova, A.N. (2018). Razvitie social'nogo intellekta budushchih uchitelej nachal'nyh klassov [The Development of Social Intelligence of Future Primary School Teachers] (PhD dissertation). Almaty. (in Russian).

Vachkov, I.V. (2007). Osnovy tekhnologii gruppovogo treninga. Psihotekhniki [Basics of group training technology. Psychotechnics]. Moscow: Publishing house "Os'-89". (In Russian).

Xavier Job, Louise Kirsch, Sandra Inard, Gabriel Arnold, \& Malika Auvray (2019). Spatial perspective taking is related to social intelligence and attachment style. Personality and Individual Differences, 168. Available at: https://doi.org/10.1016/j.paid.2019.109726

Yermentaeyeva, A., Aurenova, M., Uaidullakyzyphd, E., Ayapbergenovaphd, A., \& Muldabekova, K. (2014) "Social Intelligence as a Condition for the Development of Communicative Competence of the Future Teachers". Procedia - Social and Behavioral Sciences, 116, 4758-4763. Available at: https://doi.org/10.1016/j.sbspro.2014.01.1021 